\title{
Silencing VEGFR-2 Hampers Odontoblastic Differentiation of Dental Pulp Stem Cells
}

\author{
Kajohnkiart Janebodin ${ }^{1,2,3}$, Rakchanok Chavanachat ${ }^{4}$, Aislinn Hays ${ }^{1,2,5}$ and \\ Morayma Reyes Gil5*
}

\begin{abstract}
${ }^{1}$ Department of Pathology, University of Washington, Seattle, WA, United States, ${ }^{2}$ Institute for Stem Cell and Regenerative Medicine, University of Washington, Seattle, WA, United States, ${ }^{3}$ Department of Anatomy, Faculty of Dentistry, Mahidol University, Bangkok, Thailand, ${ }^{4}$ Department of Bioengineering, University of Washington, Seattle, WA, United States, ${ }^{5}$ Albert Einstein College of Medicine, Montefiore Medical Center, Bronx, NY, United States
\end{abstract}

OPEN ACCESS

Edited by:

Mikihito Kajiya,

Hiroshima University, Japan

Reviewed by:

Waruna Lakmal Dissanayaka, The University of Hong Kong, China Michela Pozzobon,

University of Padua, Italy

*Correspondence:

Morayma Reyes Gil mreyesgi@montefiore.org

Specialty section:

This article was submitted to

Stem Cell Research,

a section of the journal

Frontiers in Cell and Developmental

Biology

Received: 09 February 2021

Accepted: 28 May 2021

Published: 25 June 2021

Citation:

Janebodin K, Chavanachat $R$,

Hays A and Reyes Gil M (2021)

Silencing VEGFR-2 Hampers Odontoblastic Differentiation of Dental Pulp Stem Cells.

Front. Cell Dev. Biol. 9:665886. doi: 10.3389/fcell.2021.665886
Dental pulp stem cells (DPSCs) are a source of postnatal stem cells essential for maintenance and regeneration of dentin and pulp tissues. Previous in vivo transplantation studies have shown that DPSCs are able to give rise to odontoblastlike cells, form dentin/pulp-like structures, and induce blood vessel formation. Importantly, dentin formation is closely associated to blood vessels. We have previously demonstrated that DPSC-induced angiogenesis is VEGFR-2-dependent. VEGFR-2 may play an important role in odontoblast differentiation of DPSCs, tooth formation and regeneration. Nevertheless, the role of VEGFR-2 signaling in odontoblast differentiation of DPSCs is still not well understood. Thus, in this study we aimed to determine the role of VEGFR-2 in odontoblast differentiation of DPSCs by knocking down the expression of VEGFR-2 in DPSCs and studying their odontoblast differentiation capacity in vitro and in vivo. Isolation and characterization of murine DPSCs was performed as previously described. DPSCs were induced by VEGFR-2 shRNA viral vectors transfection $(\mathrm{MOI}=10: 1)$ to silence the expression of VEGFR-2. The GFP+ expression in CopGFP DPSCs was used as a surrogate to measure the efficiency of transfection and verification that the viral vector does not affect the expression of VEGFR-2. The efficiency of viral transfection was shown by significant reduction in the levels of VEGFR2 based on the Q-RT-PCR and immunofluorescence in VEGFR-2 knockdown DPSCs, compared to normal DPSCs. VEGFR-2 shRNA DPSCs expressed not only very low level of VEGFR-2, but also that of its ligand, VEGF-A, compared to CopGFP DPSCs in both transcriptional and translational levels. In vitro differentiation of DPSCs in osteoodontogenic media supplemented with BMP-2 (100 ng/ml) for 21 days demonstrated that CopGFP DPSCs, but not VEGFR-2 shRNA DPSCs, were positive for alkaline phosphatase (ALP) staining and formed mineralized nodules demonstrated by positive Alizarin Red S staining. The expression levels of dentin matrix proteins, dentin matrix protein-1 (Dmp1), dentin sialoprotein (Dspp), and bone sialoprotein (Bsp), were also up-regulated in differentiated CopGFP DPSCs, compared to those in VEGFR-2 shRNA DPSCs, suggesting an impairment of odontoblast differentiation in VEGFR-2 shRNA DPSCs. In vivo subcutaneous transplantation of DPSCs with hydroxyapatite (HAp/TCP) 
for 5 weeks demonstrated that CopGFP DPSCs were able to differentiate into elongated and polarized odontoblast-like cells forming loose connective tissue resembling pulplike structures with abundant blood vessels, as demonstrated by H\&E, Alizarin Red S, and dentin matrix staining. On the other hand, in VEGFR-2 shRNA DPSC transplants, odontoblast-like cells were not observed. Collagen fibers were seen in replacement of dentin/pulp-like structures. These results indicate that VEGFR-2 may play an important role in dentin regeneration and highlight the potential of VEGFR-2 modulation to enhance dentin regeneration and tissue engineering as a promising clinical application.

Keywords: VEGFR-2, dental pulp stem cells, tooth development, tooth regeneration, dental pulp, angiogenesis, VEGF, odontoblasts

\section{INTRODUCTION}

Dental pulp stem cells (DPSCs), a type of neural crest derived mesenchymal stem cells, have been isolated from the dental pulp, a loose connective tissue located in the center innermost part of tooth structure (Janebodin et al., 2011). Compare to other types of stem cells, this dental tissue-derived stem cell is considered a promising source of adult stem cells for regenerative dentistry and medicine given its accessibility, tremendous expansion and differentiation capacity. Isolation of DPSCs is a less invasive method compared to other sources of mesenchymal stem cells. DPSCs can be generated from various sources of dental tissues considered biological wastes such as wisdom teeth, embedded teeth, supernumerary teeth and inflamed teeth (Gronthos et al., 2000; Huang et al., 2008; Tomasello et al., 2017; Paz et al., 2018). Additionally, several studies have demonstrated its potential in tissue regeneration both in vitro and in vivo animal models (Gronthos et al., 2002; Victor and Reiter, 2017; Kabatas et al., 2018; Yamada et al., 2019; Sui et al., 2020).

We and others have shown that DPSCs exhibited in vitro multipotential capacity by differentiating to a variety of cell types such as osteoblasts, chondrocytes, adipocytes, neurons and smooth muscle cells (Gronthos et al., 2000; Janebodin et al., 2011; Shi et al., 2020). Moreover, in vivo studies revealed that DPSC transplants exhibit versatile ability for tissue regeneration in various specific conditions and animal models (Kerkis et al., 2008; Martinez-Sarra et al., 2017; Fernandes et al., 2018; Ullah et al., 2018). Research interest in DPSCs has increased with a hope to manipulate this stem cell for potential future clinical applications relating to both dental and non-dental tissue regeneration and diseases (Paz et al., 2018; Yamada et al., 2019).

The potential of DPSCs for regeneration purposes is not only based on their intrinsic differentiation capacity, but also their paracrine function such as c, neurotrophic, and immunomodulating abilities (Bronckaers et al., 2013; Luo et al., 2018; Andrukhov et al., 2019). Vascular endothelial growth factor (VEGF) signaling has been shown important for DPSCs-induced angiogenesis (Janebodin et al., 2013). Recently, VEGF has been shown to be important for the development and repair of skeletal tissue such as bone and cartilage ( $\mathrm{Hu}$ and Olsen, 2016b). Osteogenic cells and hypertrophic chondrocytes express high levels of VEGF during intramembranous and intracartilaginous bone formation, respectively (Jacobsen et al., 2008; Berendsen and Olsen, 2014; Duan et al., 2016). In addition, several studies suggest that VEGF can stimulate osteoblast differentiation $(\mathrm{Hu}$ and Olsen, 2016a). Dysfunction of VEGF signaling results in defective osteoblast differentiation and osteogenesis (Liu et al., 2012). VEGF is notably expressed in multiple cell types including endothelial cells, osteoblasts, bone marrow and dental mesenchymal stem cells (Liu et al., 2012; Janebodin et al., 2013; Buettmann et al., 2019).

Dental pulp stem cells are important for dentin and tooth regeneration. Previous in vivo transplantation studies have shown that DPSCs were able to give rise to odontoblast-like cells (OLCs), form dentin/pulp-like structures, and induce blood vessel formation. Dentin formation was also found closely related to blood vessels (Janebodin et al., 2011). We have previously shown that DPSC-induced angiogenesis is VEGFR-2dependent (Janebodin et al., 2013). However, the role of VEGFR2 signaling in odontoblast differentiation of DPSCs is still not well understood.

In this present study, we aimed to investigate the role of VEGFR-2 signaling for odontoblastic differentiation of DPSCs. Murine DPSCs were isolated and well characterized from neonatal dental pulp tissue of first and second mandibular molar teeth. DPSCs were expanded and the expression of VEGFR-2 was silenced using a specific VEGFR-2 shRNA viral vector. The efficiency of silencing was evaluated in VEGFR-2 shRNA treated DPSCs compared to the control DPSCs transfected by CopGFP shRNA by determining both transcriptional and translational levels. Afterward, the odontogenic differentiation capacity of DPSCs in these two groups was examined both in vitro and in vivo.

\section{MATERIALS AND METHODS}

\section{Mouse Housing and Husbandry}

All mouse experiments were performed in accordance with approved Institutional Animal Care and Use Committee (IACUC) guidelines, University of Washington. Mice were originally purchased from the Jackson Laboratory. Mice were housed in a specific-pathogen-free (SPF) environment in ventilated cages with filter tops (Allentown Inc., Allentown, NJ, United States). A maximum of 5 mice were housed together 
in the same cage. Mice were maintained in standard light/dark cycle (6:00 a.m. lights on, 6:00 p.m. lights off), standard food (5058 mouse breeding food), standard temperature $\left(68-79^{\circ} \mathrm{F}\right)$, and no environmental restriction. Mice were allocated randomly to control and experimental groups.

\section{Isolation, Culture and Characterization of Murine DPSCs}

Dental pulp tissues were dissected and pooled from 5-day-old neonatal murine teeth. DPSCs were isolated, cultured, expanded, and characterized as previously described (Janebodin et al., 2011). Briefly, dental pulp from lower molar teeth was gently isolated and kept in stem cell media described below. The tissue was washed with phosphate buffer saline (PBS) (HyClone). To release cells, the extracellular matrix was digested with Dispase II (1.2 units $/ \mathrm{ml})$, Collagenase IV $(2 \mathrm{mg} / \mathrm{ml})$ (Worthington) supplemented with $\mathrm{CaCl}_{2}(2 \mathrm{mM})$ in $\mathrm{PBS}$ for $1 \mathrm{~h}$ at $37^{\circ} \mathrm{C}$. Then, an equal volume of stem cell media was added to the digested tissue prior to filtering through $70 \mathrm{~mm}$ nylon cell strainers (BD Falcon) and centrifuging at $300 \times g$ for $10 \mathrm{~min}$ at room temperature. Cells were subsequently resuspended in stem cell media and single cell suspensions were plated at a density of 1000 cells $/ \mathrm{cm}^{2}$.

Cells were cultured at $37^{\circ} \mathrm{C}$ under $5 \% \mathrm{O}_{2}$ and $5 \% \mathrm{CO}_{2}$ in stem cell media, containing a final concentration of 60\% low-glucose DMEM (Gibco, Invitrogen), 40\% MCDB201 (Sigma), 2\% fetal calf serum (HyClone), insulin-transferrinselenium (ITS) (Sigma), linoleic acid with bovine serum albumin (LA-BSA) (Sigma), $10^{-9} \mathrm{M}$ dexamethasone (Sigma), $10^{-4} \mathrm{M}$ ascorbic acid 2-phosphate (Sigma), 100 units $/ \mathrm{ml}$ penicillin with $100 \mathrm{mg} / \mathrm{ml}$ streptomycin (HyClone), and $1 \times 10^{3}$ units/ml leukemia-inhibitory factor (LIF-ESGRO, Millipore), $10 \mathrm{ng} / \mathrm{mL}$ EGF (Sigma) and $10 \mathrm{ng} / \mathrm{mL}$ PDGF-BB (R\&D) (Breyer et al., 2006). Once more than $50 \%$ cell confluent, they were detached with $0.25 \%$ trypsin-EDTA (Invitrogen) and replated at a 1:4 dilution under the same culture condition with fresh media. Differentiation capacity of cultured cells was determined by in vitro multi-differentiation to bone, cartilage and fat cells as previously described (Gronthos et al., 1994; Gregoire, 2001; Dahlin et al., 2014). The osteo-odontogenic media contains serum-free media with $10 \%$ FBS, $10 \mathrm{mM}$ $\beta$-glycerophosphate, $0.2 \mathrm{mM} \mathrm{L}$-ascorbic acid, and $100 \mathrm{nM}$ dexamethasone. The chondrogenic media contains serum-free high-glucose DMEM, 1\% ITS+ premix (BD Biosciences), $50 \mathrm{mg} / \mathrm{mL}$ ascorbic acid, $100 \mathrm{nM}$ dexamethasone, supplemented with $10 \mathrm{ng} / \mathrm{ml}$ TGF- $\beta 3$ (Shenandoah Biotech). The adipogenic media contains serum-free media supplemented with $10 \%$ horse serum, $100 \mu \mathrm{M}$ indomethacin (Alfa Aesar), $0.5 \mathrm{mM}$ 3-isobutyl-1methyl-xanthine (ACROS) and $1 \mu \mathrm{M}$ dexamethasone.

\section{Silencing VEGFR-2 in Murine DPSCs}

Murine DPSCs were stably transfected with VEGFR-2 shRNA to silence the expression of VEGFR-2 as per manufacturer's protocol. Briefly, cells $\left(1000\right.$ cells $\left./ \mathrm{cm}^{2}\right)$ were plated and cultured in stem cell media for $24 \mathrm{~h}$. DPSCs were allowed to proliferate until $70 \%$ confluent before viral transfection. Then, cells were cultured in stem cell media with polybrene $(5 \mu \mathrm{g} / \mathrm{ml})$ to increase binding between the pseudoviral capsid and the cell membrane. Cells were infected by the VEGFR-2 shRNA lentiviral particles (Santa Cruz Biotechnology, Santa Cruz, CA, United States) with 10:1 of multiplicity of infection (MOI), then mixed gently, and incubated overnight. CopGFP control lentiviral particles (Santa Cruz Biotechnology) were also used as control to evaluate transduction efficiency at the similar MOI used in VEGFR-2 shRNA lentiviral particles. After overnight transduction, infected cells were replaced with stem cell media without polybrene and incubated overnight. To select stable infected cells expressing the shRNA, we expanded cells one more time in stem cell media overnight, and then selected them by exposure to puromycin dihydrochloride $(5 \mu \mathrm{g} / \mathrm{ml})$ (Sigma). The infected cells were cultured in puromycin-containing stem cell media until the resistant cells were identified. The homogeneous population of resistant cells was observed by the expression of Green Fluorescence Protein (GFP) in cells transduced with CopGFP control lentiviral particles. To determine the knockdown efficacy, the level of VEGFR-2 and VEGF-A in both silencing and control groups was determined by mRNA and protein levels through real-time PCR and immunofluorescence analyses.

\section{Immunofluorescence}

Cells were fixed with $4 \%$ formaldehyde/PBS for $5 \mathrm{~min}$, washed with $1 \%$ BSA in $0.1 \%$ Triton-X $100 / \mathrm{PBS}$, and stained with primary antibodies as described in Supplementary Table 1 incubated overnight at $4^{\circ} \mathrm{C}$. Goat-derived Alexa 594-conjugated secondary antibodies (Invitrogen) were diluted at 1:800 and incubated for $1 \mathrm{~h}$. Cells were stained with 4', 6-diamine-2-phenylindol (DAPI) at 1:1000 to visualize the nuclei. All antibodies were diluted in $1 \%$ BSA in $0.1 \%$ Triton-X 100/PBS. We used IgG isotype from the species made for the primary antibody $(0.1 \mathrm{ug} / \mathrm{ml})$ (Vector Laboratories Inc., Burlingame, CA, United States), were included for all staining.

\section{In vitro Osteo-Odontogenic Differentiation}

VEGFR-2 shRNA treated DPSCs and CopGFP treated DPSCs $\left(2 \times 10^{4}\right.$ cells $/ \mathrm{cm}^{2}, n=4$ wells/group) were incubated overnight in stem cell media at $37^{\circ} \mathrm{C}$ under $5 \% \quad \mathrm{O}_{2}$ and $5 \% \quad \mathrm{CO}_{2}$. After $24 \mathrm{~h}$, each cell type was separately cultured in BMP2 media, $\beta$-glycerophosphate plus ascorbic acid (BGP + Vit. C) media, VEGF media for 21 days to evaluate the osteoodontogenic differentiation capacity with media change every 3 days. BMP- 2 media is serum-free media containing $10 \% \mathrm{FBS}$, $100 \mathrm{ng} / \mathrm{ml}$ BMP-2 (Shenandoah Biotech), $0.2 \mathrm{mM} \mathrm{L-ascorbic}$ acid, and $100 \mathrm{nM}$ dexamethasone (Hu et al., 2004). BGP + Vit. $\mathrm{C}$ media is serum-free media containing $10 \%$ FBS, $10 \mathrm{mM}$ $\beta$-glycerophosphate (CalBiochem), $0.2 \mathrm{mM}$ L-ascorbic acid, and $100 \mathrm{nM}$ dexamethasone (Song et al., 2009). VEGF media is serum-free media containing $10 \mathrm{ng} / \mathrm{ml}$ VEGF (R\&D) (Forgues et al., 2019). Serum-free media is 60\% low-glucose DMEM, 40\% MCDB201, ITS, LA-BSA, $10^{-9} \mathrm{M}$ dexamethasone, $10^{-4} \mathrm{M}$ ascorbic acid 2-phosphate, 100 units $/ \mathrm{ml}$ penicillin with $100 \mathrm{mg} / \mathrm{ml}$ streptomycin. After differentiation, both cell 
groups were separately divided into 2 subgroups for RNA collection and staining.

\section{Alkaline Phosphatase Staining}

After differentiation, cultured cells were stained by ALP staining kit (BioVision) as per manufacturer's protocol. Briefly, the media were carefully removed from the cultured cell wells. Cells were fixed with $4 \%$ formaldehyde/PBS for $15 \mathrm{~min}$ at room temperature. Then, $500 \mu \mathrm{l}$ of wash buffer was gently added and carefully removed using a pipette. $250 \mu$ l of ALP Staining Reagent solution was carefully added to completely cover the cells in each well of a 24-well plate. Cells were incubated for $30 \mathrm{~min}$ at $37^{\circ} \mathrm{C}$ before washed gently with $500 \mu \mathrm{l}$ of wash buffer for 3 times. $300 \mu \mathrm{l}$ of wash buffer was added and stained cells were imaged using a light microscope.

\section{Alizarin Red S Staining}

Cultured cells were stained by Alizarin Red S staining kit (ScienCell Research Laboratories) as per manufacturer's protocol. Briefly, the media were carefully removed from the cultured cell wells and cells were washed three times with PBS. Cells were fixed with $4 \%$ formaldehyde/PBS for $15 \mathrm{~min}$ at room temperature. The fixative solution was removed and cells were washed three times with deionized water. The water was removed and $500 \mu \mathrm{l}$ of $40 \mathrm{mM}$ Alizarin Red S dye was added per well. Cells were incubated at room temperature for $30 \mathrm{~min}$ with gentle shaking. The dye was removed and cells were washed five times with deionized water before taking images. For tissue transplants, the sections were deparaffinized and hydrated to $70 \%$ ethanol. Then, the tissue sections were fixed with $10 \%$ formaldehyde/PBS for $15 \mathrm{~min}$ at room temperature before staining following the protocol described above.

\section{Real-Time PCR Analysis}

Dental pulp stem cells were extracted for total RNA by using the RNeasy Mini kit (Qiagen) according to the manufacturer's protocol. Quantity and purity of RNA was determined by 260/280 nm absorbance. First-strand cDNA was synthesized from $500 \mathrm{ng}$ of RNA using the High Capacity cDNA synthesis kit (Applied Biosystems) per manufacturer's protocols using a randomized primer. Real-time PCR primers are included in Supplementary Table 2.

A $20 \mathrm{ng}$ of CDNA for Q-RT-PCR were prepared using the SYBR green PCR master mix (Applied Biosystems). Reactions were processed by the ABI $7900 \mathrm{HT}$ PCR system with the following parameters: $50^{\circ} \mathrm{C} / 2 \mathrm{~min}$ and $95^{\circ} \mathrm{C} / 10 \mathrm{~min}$, followed by 40 cycles of $95^{\circ} \mathrm{C} / 15 \mathrm{~s}$ and $60^{\circ} \mathrm{C} / 1 \mathrm{~min}$. Results were analyzed using SDS 2.2 software and relative expression calculated using the comparative $\mathrm{Ct}$ method. The threshold cycle $(\mathrm{Ct})$ value for each gene was normalized to the $\mathrm{Ct}$ value of GAPDH. The relative mRNA expression, presented as fold change difference, was calculated by the comparative $\mathrm{Ct}$ method according to the formula: $2^{-\Delta \Delta \mathrm{Ct}}$, where $\Delta \mathrm{Ct}=\mathrm{Ct}$ targetCt GAPDH and $\Delta \Delta \mathrm{Ct}=\Delta \mathrm{Ct}$ target $-\Delta \mathrm{Ct}$ calibrator. Each sample was run in triplicate reactions for each gene. Error bars represent the standard deviation calculated from the triplicate analysis of each sample.

\section{In vivo Transplantation of DPSCs}

In accordance with approved IACUC protocols, $1 \times 10^{6}$ of VEGFR-2 shRNA treated DPSCs and CopGFP treated DPSCs were separately transplanted into 1-month-old male Rag1 null mice (Jackson Laboratory, Bar Harbor, ME, United States) by dorsal subcutaneous transplantation with hydroxyapatite tricalciumphosphate (HAp/TCP) (Zimmer) $(n=5 \mathrm{mice} / \mathrm{cell}$ type). Grafts were harvested after 5 weeks of transplantation. Transplanted tissues samples were fixed with $4 \%$ formaldehyde for $2 \mathrm{~h}$ then demineralized for 7 days in $10 \%$ EDTA at $4^{\circ} \mathrm{C}$. Then, the transplants were embedded in paraffin and cut to $5 \mu \mathrm{m}$ thick sections. Sections were analyzed by $\mathrm{H} \& \mathrm{E}$, Alizarin Red $\mathrm{S}$ and immunohistochemistry staining.

\section{Tissue Staining}

Prior to staining procedures, paraffin-embedded tissue sections were deparaffinized and hydrated to $70 \%$ ethanol. Tissues were stained with H\&E staining following the manufacturer's standard protocol. For immunohistochemistry, fixed tissue sections were permeabilized with $1 \%$ BSA in $0.1 \%$ Triton-X 100 (Sigma)/PBS for $10 \mathrm{~min}$, inhibited endogenous peroxidase activity with $0.3 \%$ hydrogen peroxide in methanol for $30 \mathrm{~min}$, and blocked nonspecific binding sites with $10 \%$ goat or horse serum (Vector Laboratories Inc., Burlingame, CA, United States) for $1 \mathrm{~h}$. Primary antibodies listed in Supplementary Table 1 were used and incubated overnight at $4^{\circ} \mathrm{C}$. Stained tissues were incubated with a biotinylated antibody at 1:100 (Vector Laboratories Inc., Burlingame, CA, United States) for $1 \mathrm{~h}$, washed and treated with the Vectastain ABC kit and 3, 3'-diaminobenzidine (DAB) substrate kit according to manufacturer's protocol (Vector Laboratories Inc., Burlingame, CA, United States).

\section{Statistical Analysis}

The number of mice were calculated using power analysis based on previous pilot studies in our laboratory (statistical power of 0.90 ; $p$ level $=0.05)$. Statistical analysis of the in vitro studies, histology, and molecular analysis results from three independent experiments were performed by the Student's $t$ test. Data are presented as mean \pm SD. $p$-values $\leq 0.001,0.005,0.05$ was considered as statistically significant.

\section{RESULTS}

\section{DPSCs Exhibited Self-Renewal and Multi-Differentiation Capacity in vitro}

Dental pulp stem cells were isolated from neonatal murine pulp tissue of lower molar teeth. Cell suspension was plated in a low cell density as a single cell deposition. After 2 days of culture in stem cell media, several cell colonies were observed (Figure 1A). Later, larger colonies of cells were seen before cell trypsinization and expansion (Figures 1B,C). Compared to undifferentiated DPSCs (Figure 1D), cultures in specific differentiation media revealed DPSCs differentiation abilities to give rise to osteoblastlike cells (positive staining for BSP and DMP-1, Figures 1E,F), 


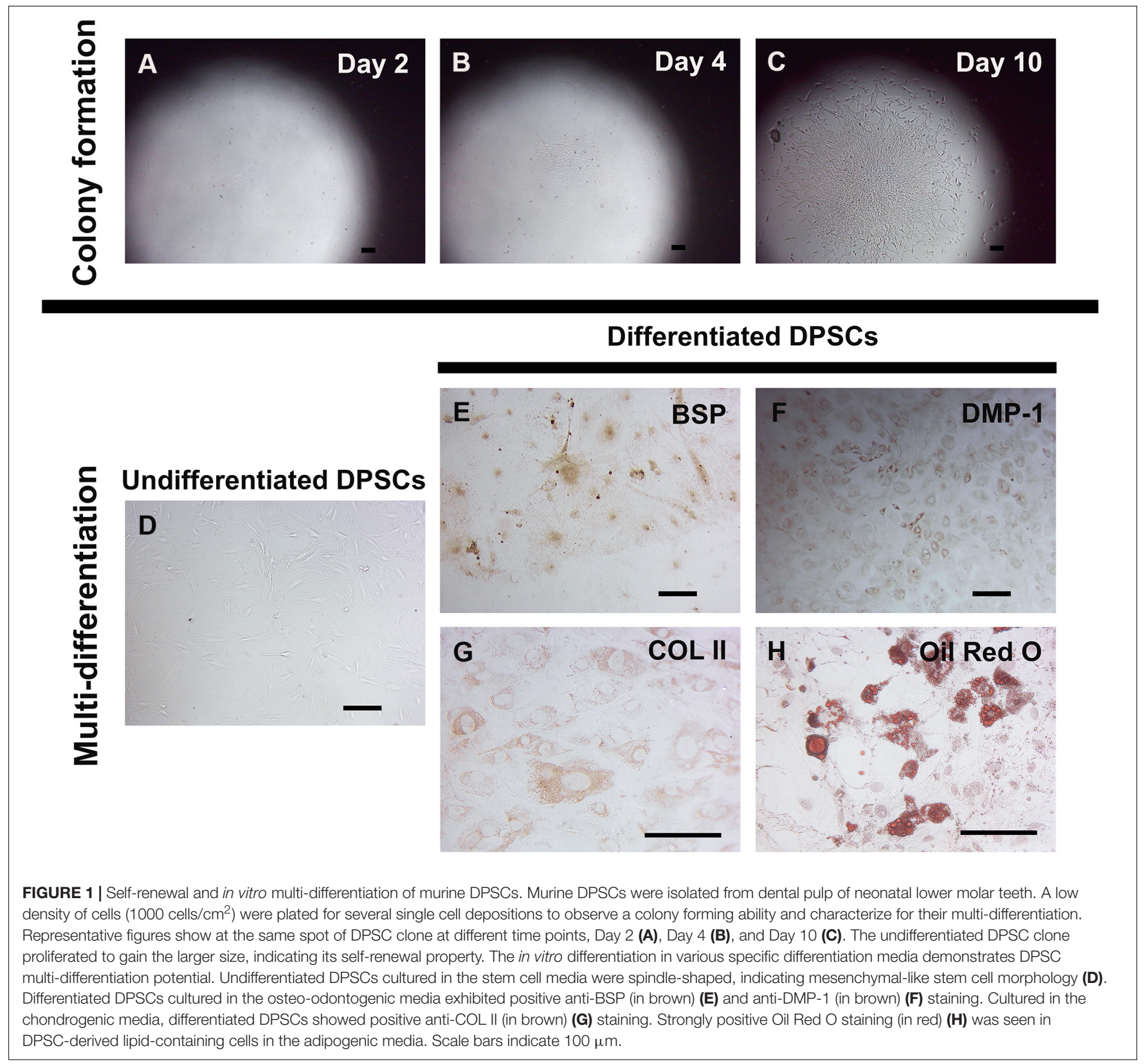

chondrocyte-like cells (positive staining for COL II, Figure 1G), and adipocytes (positive staining with Oil Red O, Figure 1H).

\section{Down-Regulation of VEGFR-2 Significantly Decreases Expression of VEGF-A in DPSCs}

In order to investigate the potential role of VEGFR-2 signaling in osteo-odontogenic differentiation of DPSCs, VEGFR-2 shRNA was utilized to silence VEGFR-2 expression in murine DPSCs. The CopGFP shRNA was also used as a control to determine the efficiency of transfection. We targeted DPSCs with both VEGFR-2 and CopGFP shRNA separately and observed approximately 100\% GFP expression in CopGFP (Figures 2A,C) but not in VEGFR-2 shRNA group (Figures 2B,D). CopGFP DPSCs expressed high levels of both VEGFR-2 and VEGF-A (Figures 2E,G,K,L). In contrast, an 8-fold decrease of Vegfr-2 expression was shown in VEGFR-2 shRNA DPSCs compared to the CopGFP control DPSCs $(* * * p<0.001)$ (Figure $2 \mathbf{K})$. The gene expression level corresponded to a dramatic decrease in VEGFR-2 immunofluorescence staining of VEGFR-2 shRNA DPSCs (Figures 2F,L). The quantification of the VEGFR-2 fluorescence intensity showed a statistically significant decrease in VEGFR-2 level in VEGFR-2 knockdown DPSCs, compared to normal DPSCs ( ${ }^{* *} p<0.005$ ) (Figure 2L). In addition, VEGFR-2 shRNA DPSCs down-regulated VEGF-A gene and protein levels $\left({ }^{*} p<0.05\right.$ and ${ }^{* *} p<0.005$, respectively), compared to the CopGFP control cells (Figures $2 \mathbf{H}, \mathbf{K}, \mathbf{L}$ ). The rabbit IgG 


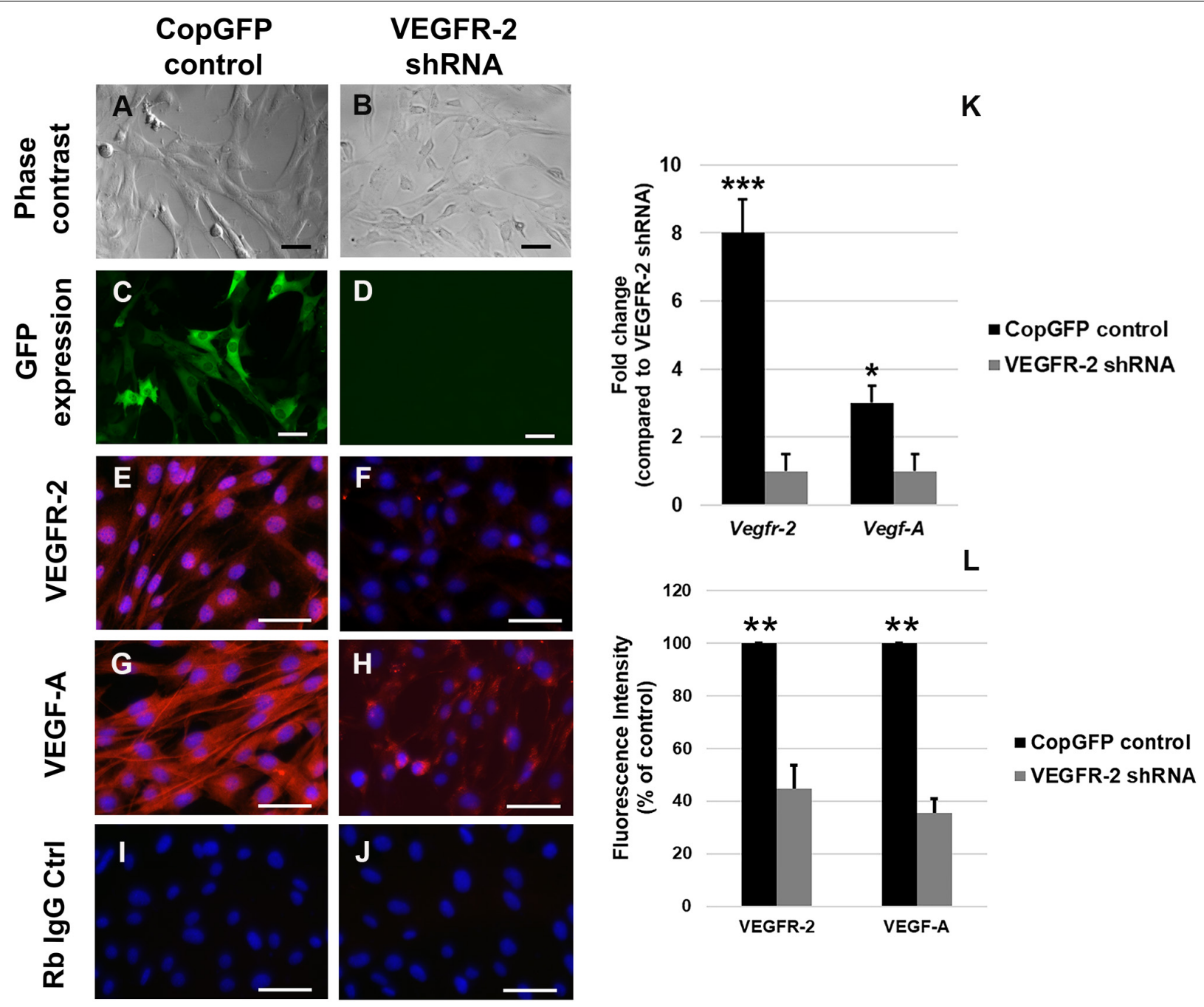

FIGURE 2 | Silencing of VEGFR-2 in murine DPSCs using the lentiviral vector. Murine DPSCs were transfected by either CopGFP control (A) or VEGFR-2 shRNA (B) Ientiviral vectors with 10:1 of $\mathrm{MOI}$ (multiplicity of infection). After transfection, both groups exhibited their regular spindle shapes, presenting no toxicity of the viral vector. The 100\% expression of GFP in CopGFP control (C) but not in VEGFR-2 shRNA group (D) was seen. The GFP+ expression in CopGFP DPSCs indicates the high efficiency of transfection. Immunofluorescence (in red) demonstrates strong positive staining of VEGFR-2 (E) and its ligand, VEGF-A (G) in CopGFP control DPSCs whereas there were very low expression of VEGFR-2 (F) and VEGF-A (H) in VEGFR-2 shRNA DPSCs. The rabbit lgG control (Rb IgG Ctrl) stained in CopGFP control (I) and VEGFR-2 shRNA DPSCs (J) were completely negative to confirm the specificity of antibodies. DAPI (in blue) was used for the nuclear staining. Scale bars indicate $100 \mu \mathrm{m}$. The bar graph (K) reveals that real-time PCR analysis showed higher expression of both Vegfr-2 and Vegf-A in CopGFP control DPSCs, compared to that in VEGFR-2 shRNA treated DPSCs. Differences in gene expression is demonstrated as the fold change of that in VEGFR-2 shRNA DPSC group. GAPDH was used as the internal control. The bar graph (L) reveals the quantification of the VEGFR-2 and VEGF-A fluorescence intensity in both normal and VEGFR-2 knockdown DPSCs by using ImageJ software. The quantification showed a statistically significant decrease in VEGFR-2 and VEGF-A levels in VEGFR-2 knockdown DPSCs, compared to normal DPSCs. The results were shown as the fluorescence intensity (\% of control). ${ }^{* \star *},{ }^{* *},{ }^{*}$ is used for significantly statistical difference at $p$-value $<0.001,0.005,0.05$, respectively. The results represent the means $\pm S D$ ( $n=5$ from each group/experiment) of three independent experiments.

control (Rb IgG Ctrl) stained in CopGFP control (Figure 2I) and VEGFR-2 shRNA DPSCs (Figure 2J) were completely negative to confirm the specificity of antibodies.

\section{VEGFR-2 Deficient DPSCs Lacked Osteo-Odontogenic Potential in vitro}

CopGFP DPSCs cultured in BMP-2 media showed strongly positive staining of ALP enzyme (in black) (Figures 3A,C,D).
In contrast, VEGFR-2 shRNA DPSCs exhibited significantly decreased ALP staining (Figures 3B,E). Few slightly ALP positive cells in VEGFR-2 shRNA DPSCs were observed (Figure 3F). In addition, abundant mineralized nodules were observed and positively stained Alizarin Red S (in red) in the CopGFP DPSCs (Figures 3G,I) while those nodules were absent in the VEGFR2 shRNA DPSCs (Figures 3H,K). A cluster of cuboidal cells were seen, indicating osteo-OLCs (Figure 3J). Nevertheless, Alizarin Red S stained slightly positive in the cytoplasmic 

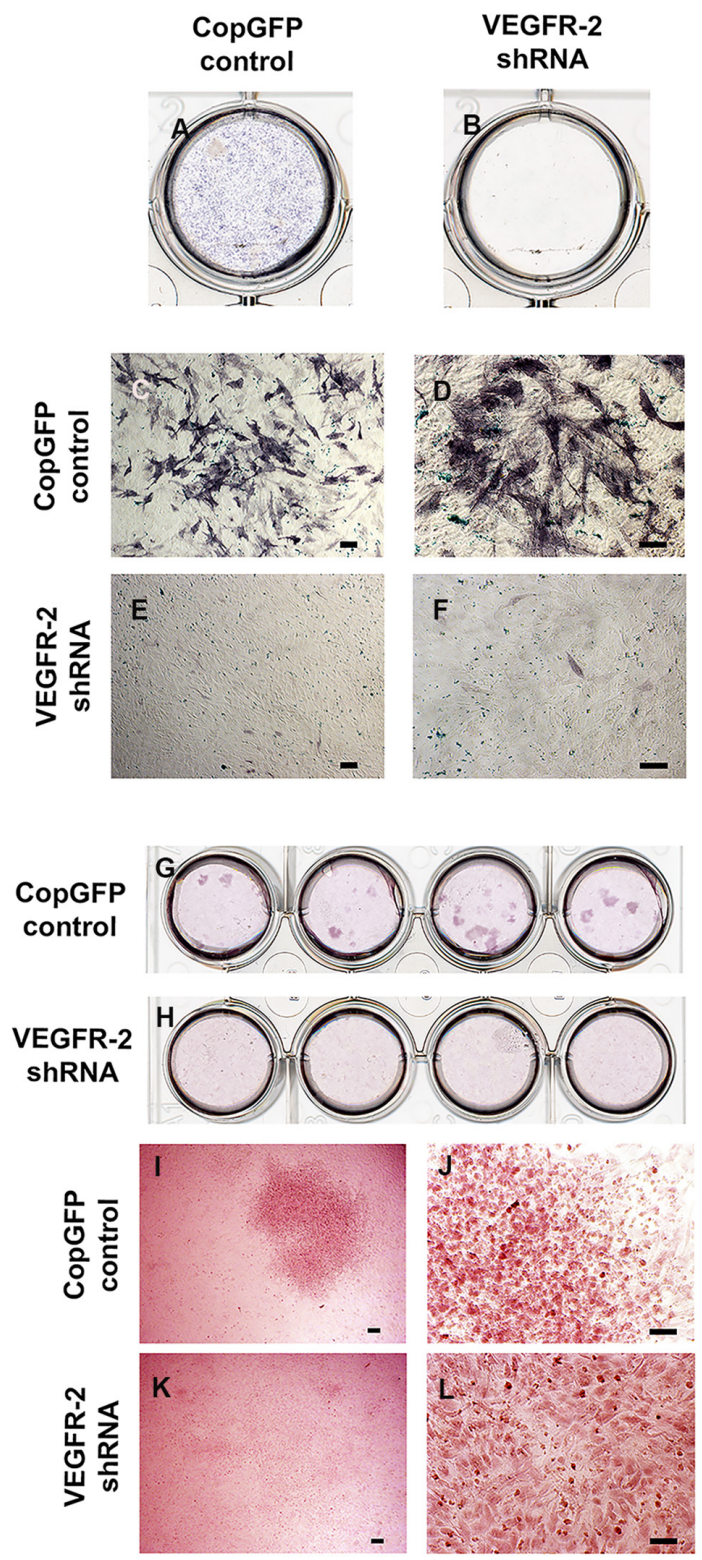

FIGURE 3 | Alkaline phosphatase and Alizarin Red S staining in CopGFP control and VEGFR-2 shRNA DPSCs after a culture in osteo-odontogenic BMP-2 media. Alkaline phosphatase staining demonstrated a dissimilar result between CopGFP control (A) and VEGFR-2 shRNA DPSCs (B) after osteo-odontogenic induction in BMP-2 media. Abundant positive alkaline phosphatase stained cells (in dark-bluish purple) were shown in CopGFP control DPSCs, suggesting DPSCs undergoing osteo-odontogenesis (C,D). Few slightly positive stained for alkaline phosphatase staining were found in VEGFR-2 shRNA DPSCs (E,F). Alizarin Red S staining demonstrated a different result between CopGFP control and VEGFR-2 shRNA DPSCs after osteo-odontogenic induction in BMP-2 media. Several Alizarin Red S positive mineralized nodules were detected in differentiated CopGFP control DPSCs (G). There was absence of mineralized nodule found in differentiated VEGFR-2 shRNA DPSCs $\mathbf{( H )}$. A representative figure reveals a low magnification of Alizarin Red S positive mineralized nodules in the CopGFP control (I). The higher magnification of the nodule showed cuboidal-like cells, resembling osteo-odontoblast-like cells (J). VEGFR-2 shRNA DPSCs did not show any mineralized nodule formation (K) but they were undifferentiated spindle-shaped (L). Scale bars indicate $100 \mu \mathrm{m}$. compartment of VEGFR-2 shRNA DPSCs due to the intracellular calcium contents (Figure 3L). Remarkably, VEGFR-2 shRNA DPSCs maintained a spindle-shaped morphology, resembling an undifferentiated state. Additionally, immunocytochemistry showed certain positive cells of anti-DMP-1 (Figure 4A) and antiDSP (Figure 4B) staining (in brown) in differentiated CopGFP control DPSCs but slightly stained cells in VEGFR-2 shRNA DPSCs (Figures 4D,E). The rabbit IgG control (Rb IgG Ctrl) stained in CopGFP control (Figure 4C) and VEGFR-2 shRNA DPSCs (Figure 4F) were completely negative to confirm the specificity of antibodies. VEGFR-2 shRNA DPSCs also downregulated the expression of Dmp-1,Dspp, and Bsp; however, only Dmp-1 and Bsp showed a significant difference compared to the CopGFP DPSCs $\left({ }^{*} p<0.05\right)$ (Figure 4G). Cultured in BGP + Vit. C media, occasional strongly ALP positive cells (Figures 5A,C,E) were seen in the control DPSCs but not in the VEGFR-2 shRNA DPSCs (Figures 5B,D,F). Some Alizarin Red S positive nodules were present in the CopGFP cells whereas those were not detected in the VEGFR-2 shRNA cells (Figure 5M). Similarly, cultured in VEGF media, few ALP positive cells were present in only the CopGFP group (Figures 5G,I,K), not in the VEGFR-2 shRNA group (Figures $\mathbf{5} \mathbf{H}, \mathbf{J}, \mathbf{L}$ ). However, there were no mineralized nodules observed in both CopGFP and VEGFR-2 shRNA groups (Figure 5N).

\section{VEGFR-2 Deficient DPSCs Were Unable to Give Rise to Odontoblast-Like Cells and Form Pulp-Like Structures After Transplantation}

H\&E staining revealed the overall morphology of CopGFP DPSC transplants (Figures 6A-C) and VEGFR-2 shRNA DPSC transplants (Figures 6G-I). In vivo transplantation of CopGFP DPSCs demonstrated elongated and polarized cells (Figures 6D-F; arrowheads) running perpendicularly to hydroxyapatite/tricalcium phosphate (HAp/TCP), resembling the morphology of OLCs. In addition, a formation of pulplike structure was revealed by the presence of loose connective tissue with capillaries containing RBCs (Figures 6D-F) in CopGFP DPSC transplants, mimicking pulp-like tissues in the natural teeth. In contrast, VEGFR-2 shRNA DPSCs transplants lacked OLCs and pulp-like structures. Instead, there was only a formation of disperse collagenous tissue (Figures 6J-L).

In the cross-section of the tooth, Alizarin Red S showed the strongly positive staining of dentin and odontoblasts; it also exhibited the histology of dental pulp which is a vascularized loose connective tissue (Figure 7A). A transplanted tissue generated by the CopGFP DPSCs stained positive for Alizarin Red $S$ and also demonstrated the presence of OLCs (Figures 7B,C; arrowheads) with pulp-like-tissues (Figures 7B,C). In contrast, VEGFR-2 shRNA DPSC transplants showed disorganized tissues faintly positive for Alizarin Red $S$ staining (Figures 7D,E). In the tooth section, anti-DMP1 and anti-DSP staining was positive in dentin and intense in odontoblasts (Figures 7F,G). Interestingly, the transplanted tissues generated by the control cells also showed strong signal of immunohistochemistry for DMP-1 and DSP proteins in OLCs 


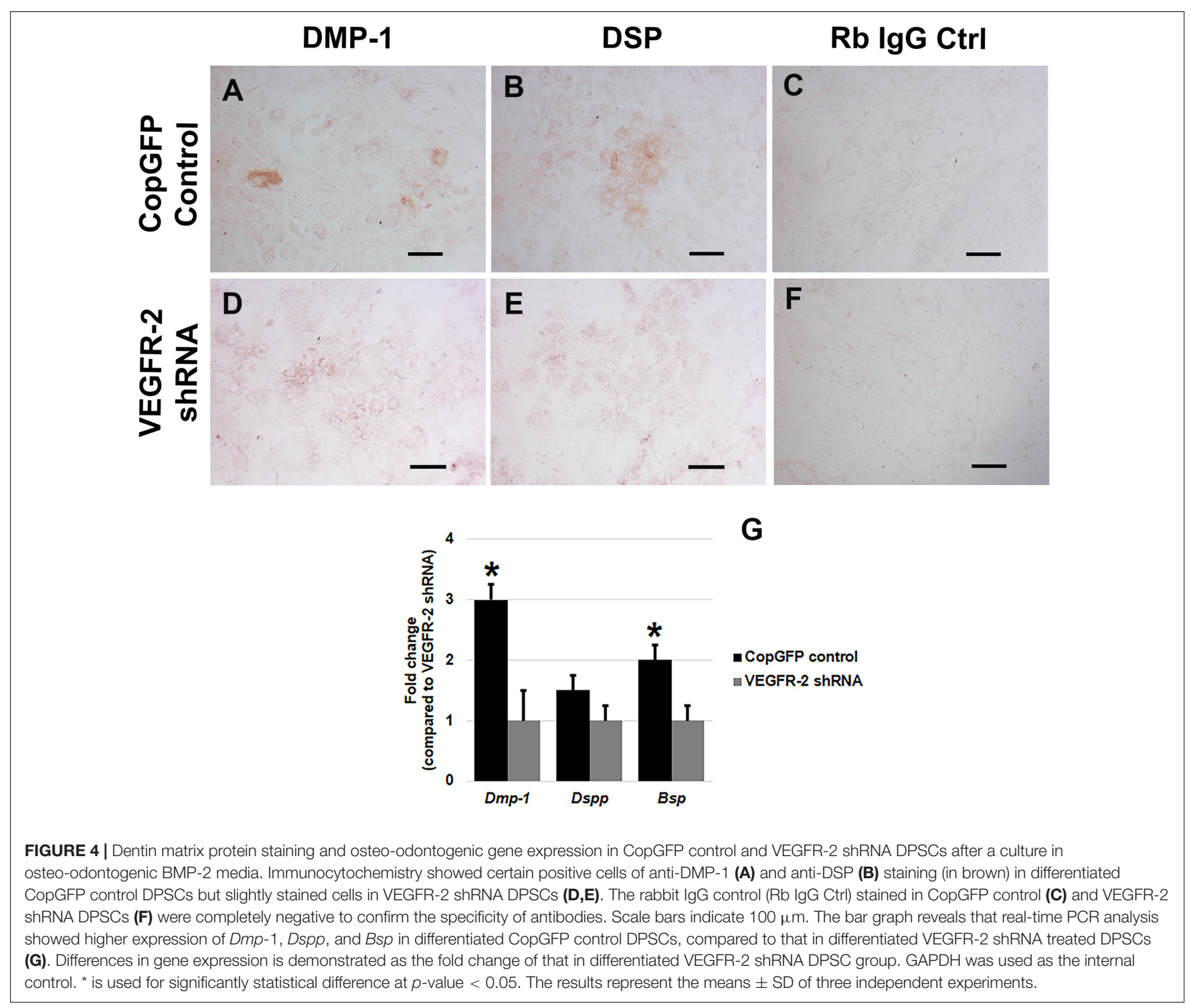

(Figures 7I,J; arrowheads) and matrix (Figures 7I,J; asterisks). In contrast, we were not able to observe positive DMP-1 and DSP staining in the VEGFR-2 shRNA DPSC transplants (Figures $7 \mathbf{L}, \mathbf{M}$ ). Rb IgG control was used as a negative control (Figures $7 \mathbf{H}, \mathbf{K}, \mathbf{N}$ ).

\section{DISCUSSION}

Dental pulp stem cells which are isolated from tooth pulp tissues have been shown to play an important role in dentin/pulp repair and regeneration (Gronthos et al., 2002; Paz et al., 2018). Recent studies have revealed that DPSCs have not only an odontogenic capacity but also an angiogenic potential (Martinez-Sarra et al., 2017; Yamada et al., 2019; Shi et al., 2020; Sui et al., 2020). We have previously shown that angiogenesis induced by DPSCs is regulated by VEGFR-2 signaling (Janebodin et al., 2013). However, the relevance of VEGFR-2 signaling in odontogenesis and dentinogenesis is still undetermined. In this study, we investigated the potential role of VEGFR-2 for odontogenic capacity of murine DPSCs both in vitro and in vivo.

First, DPSCs were isolated from mouse neonatal-derived lower molar teeth and examined for their stem cell properties as previous protocol (Janebodin et al., 2011). Plating cells at low density close to a single cell deposition revealed formation of several cell colonies. As expected, those colonies increased in size with longer culture time, highlighting their self-renewal capacity. Moreover, DPSCs cultured in various differentiation media exhibited characteristic morphological changes combined with the positive staining for osteoblastic, chondrogenic, and adipogenic. These results correspond to previous studies confirming the mesenchymal stem cell's properties of DPSCs (Gronthos et al., 2000; Huang et al., 2008; Janebodin et al., 2011; Paz et al., 2018).

Next, we silenced the expression of VEGFR-2 in DPSCs by using the VEGFR-2 shRNA lentiviral transfection. The shRNA 


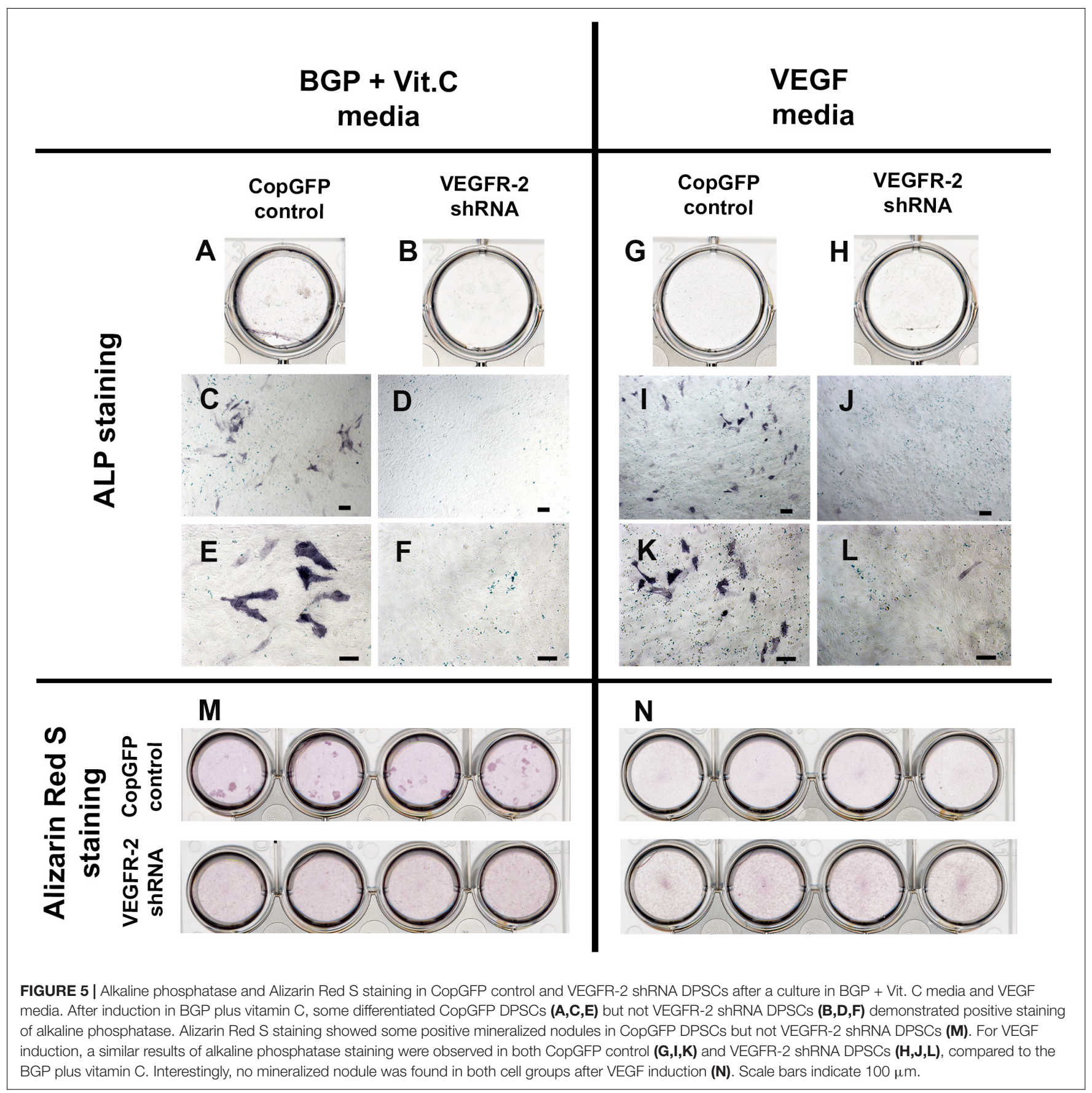

(short hairpin RNA) delivery into mammalian cells is considered a powerful method to study gene functions via the cellular mechanism of RNA interference. This technique provides a stable integration of shRNA, resulting in a long-term knock down of an interested gene (Moore et al., 2010). To confirm the initial successful transfection, treated cells were selected through puromycin supplemented media. Furthermore, the CopGFP shRNA which is a non-specific viral vector conjugated with GFP was used as a control (Guryanova et al., 2006). Approximately $100 \%$ of DPSCs transfected with the CopGFP construct expressed GFP. Since both CopGFP and VEGFR-2 shRNA have the similar constructs, we assumed that transfection of DPSCs with VEGFR2 shRNA was highly efficient. To prove that, real-time PCR and immunofluorescence were used to demonstrate that the VEGFR-2 shRNA DPSCs exhibited a decrease in VEGFR-2 gene and protein expression, compared to the CopGFP control. Importantly, the transcriptional and translational level of VEGFA were also down-regulated. VEGF-A is a protein with a variety of biological functions especially in endothelial cells and pericytes such as vascular permeability, cell survival, proliferation and migration that are important in angiogenesis. VEGF-A binds to and activates VEGFR-1 and VEGFR-2 (Neufeld et al., 1999). 

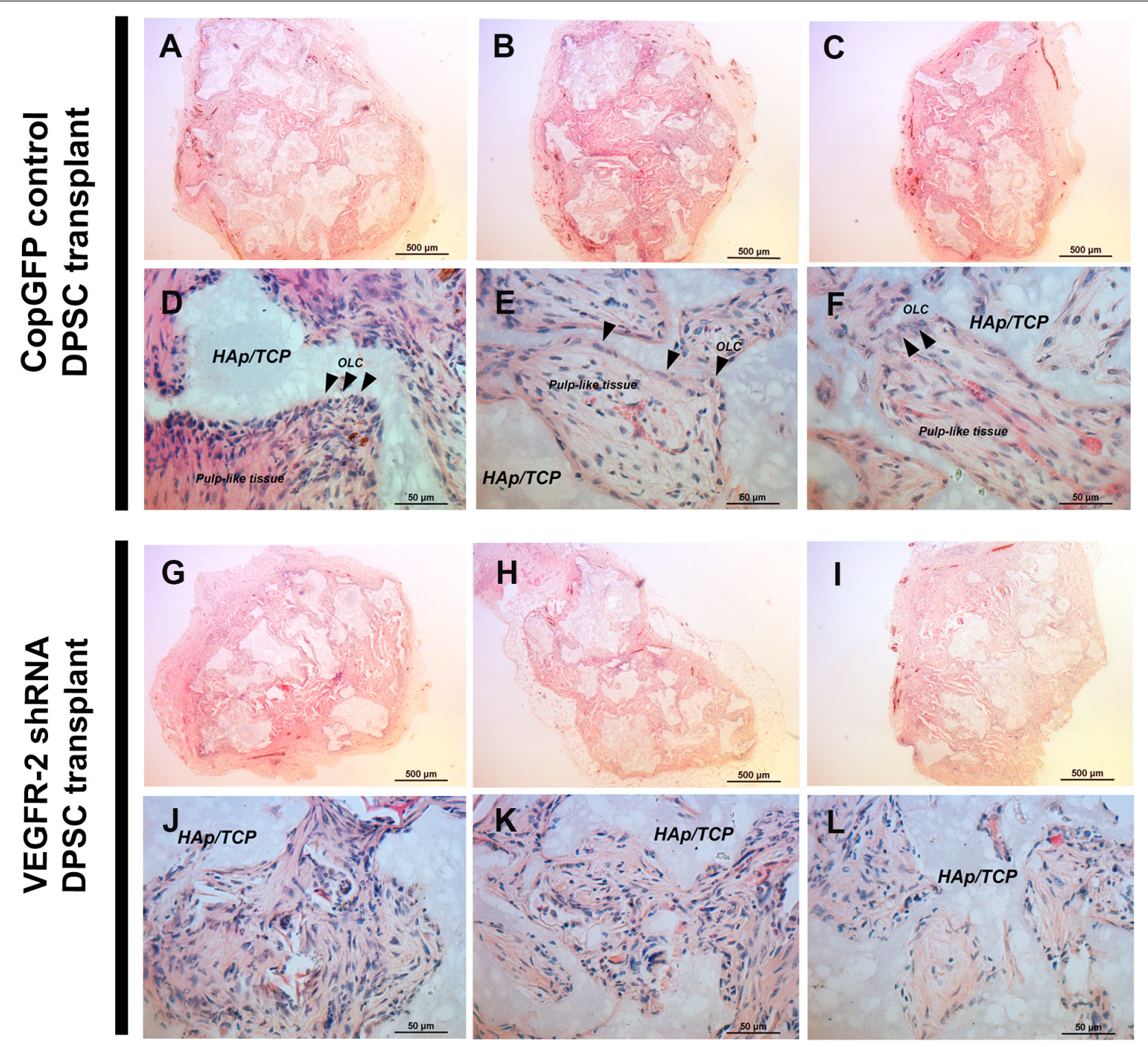

FIGURE 6 | In vivo transplantation of CopGFP control and VEGFR-2 shRNA DPSCs by H\&E staining. $1 \times 10^{6}$ cells of CopGFP control and VEGFR-2 shRNA DPSCs were separately transplanted into 1-month-old male Rag1 null mice by dorsal subcutaneous transplantation with hydroxyapatite tricalciumphosphate (HAp/TCP) ( $n=5$ mice per cell type). Transplanted tissues were harvested after 5 weeks, then proceeded and stained for analysis. H\&E staining was performed to demonstrate the morphology of CopGFP DPSC transplants [(A-C); low magnification of representative tissues] and VEGFR-2 shRNA DPSC transplants [(G-I); low magnification of representative tissues]. Scale bars indicate $500 \mu \mathrm{m}$. CopGFP DPSC transplants exhibited elongated and polarized odontoblast-like cells (OLC) (arrowheads) and more organized loose connective tissue with abundant blood vessels mimicking pulp-like structures (D-F) while VEGFR-2 shRNA DPSC transplants showed an absence of odontoblast-like cells. Instead, disorganized fibrous collagenous tissue was seen (J-L). OLC; odontoblast-like cells, HAp/TCP;

hydroxyapatite/tricalciumphosphate. Scale bars indicate $50 \mu \mathrm{m}$.

Although VEGFR-2 has a low affinity for VEGF-A, its tyrosine kinase activity is stronger than that of VEGFR-1 (Eichmann and Simons, 2012; Berendsen and Olsen, 2014). Previous studies have shown that DPSCs, a neural crest-derived mesenchymal stem cell, have pericyte-like properties capable of inducing angiogenesis through VEGFR-2/VEGF-A pathway (Janebodin et al., 2013). This suggests that the down-regulation of VEGFR-2 may regulate expression of its ligand, VEGF-A. Nevertheless, the underlying mechanism needs further investigation.
The osteo-odontogenic capacity of CopGFP and VEGFR2 shRNA DPSCs were examined by cultured in two types of osteo-odontogenic media, BMP-2 media and BGP plus vitamin $\mathrm{C}$ media. The CopGFP control cells exhibited higher osteoodontogenic potential in both media, compared to the VEGFR-2 shRNA cells based on ALP and Alizarin Red S staining. However, CopGFP cells cultured in BMP-2 media showed higher number of differentiated cells compared to those in BGP plus vitamin C media. This result underscores BMP-2 as a powerful morphogen 

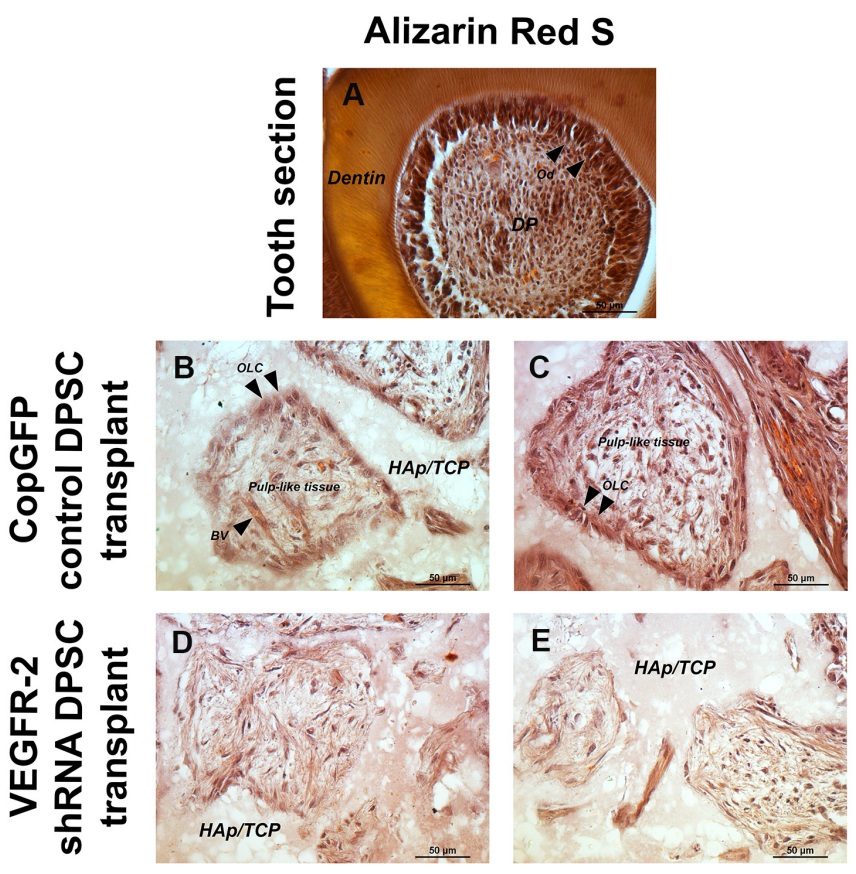

DMP-1
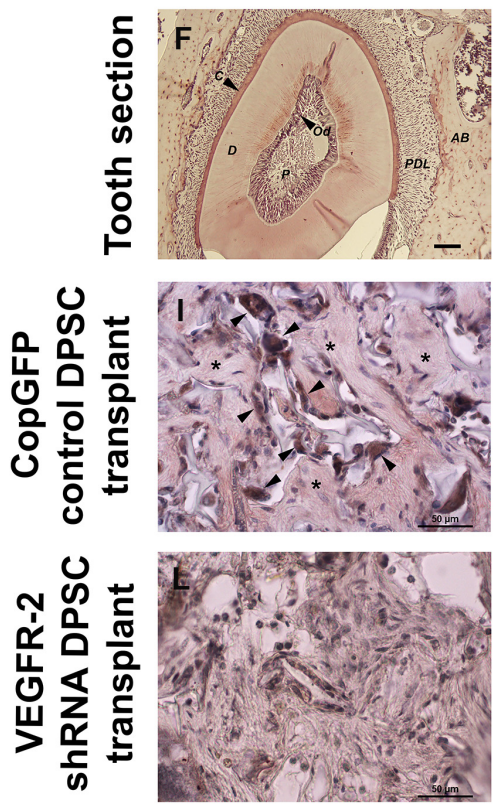

DSP
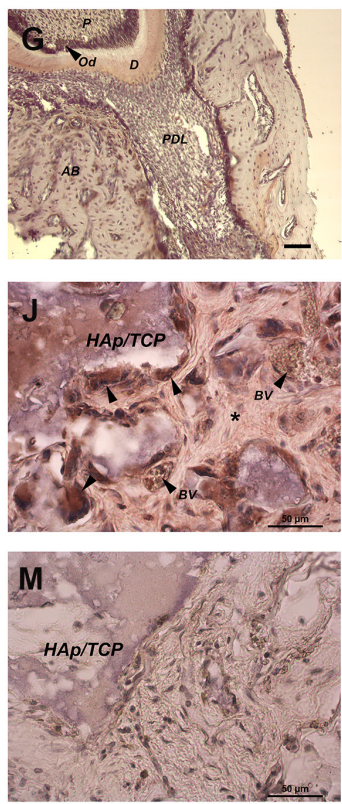

Rb IgG Ctrl
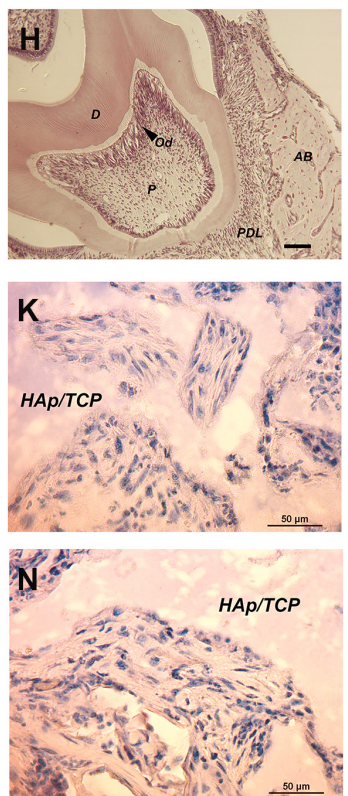

FIGURE 7 | In vivo transplantation of CopGFP control and VEGFR-2 shRNA DPSCs by Alizarin Red S staining and immunohistochemistry. Alizarin Red S staining was conducted to confirm the mineralized tissues, dental structures and morphology of CopGFP DPSC transplants and VEGFR-2 shRNA DPSC transplants. The cross-section of murine tooth was used as a positive control for Alizarin Red S staining. The positive area of Alizarin Red S showed in dentin, odontoblasts and some dental pulp regions (A). A CopGFP control DPSC transplant revealed positive staining of fibrous structure surrounding HAp/TCP with elongated and polarized odontoblast-like cells (OLC) (arrowheads). Some positive odontoblast-like cells (OLC) (arrowheads) running perpendicular to HAp/TCP and pulp-like tissues with blood capillaries were seen in CopGFP DPSC transplants (B,C). VEGFR-2 shRNA DPSC transplants only showed diffuse unpatterned cell arrangement with disorganized connective tissue (D,E). Immunohistochemistry of anti-DMP-1 and anti-DSP staining was also conducted to determine the specific dentin protein expression in the transplant tissues. The tooth sections were used as a positive control. The expression of DMP-1 and DSP was seen in dentin, cementum and alveolar bone. Both dentin matrices were very strong in the odontoblast cell layer (F,G). The CopGFP control DPSC transplants revealed the strongly positive anti-DMP-1 and anti-DSP staining in odontoblast-like cells (OCL) (arrowheads) (I,J). Its matrices were slightly stained for both markers (asterisks). The VEGFR-2 shRNA DPSC transplants showed the negative anti-DMP-1 and anti-DSP staining (L,M). The Rabbit lgG control (Rb lgG Ctrl) was used as a negative control to confirm the specificity of antibody (H,K,N). AB; alveolar bone, C; cementum, D; dentin, HAp/TCP; hydroxyapatite/tricalciumphosphate, OLC; odontoblast-like cells, P; Pulp, PDL; periodontal ligament. Scale bars indicate $50 \mu \mathrm{m}$. 
in osteoblast differentiation, bone development, formation and repair (Jorgensen et al., 2004; Marupanthorn et al., 2017). ALP plays an important role as an early osteogenic marker (Sabokbar et al., 1994). Alizarin Red S staining is a method to determine the mineralization or calcification which is a late hallmark for osteoblastic differentiation (Clark et al., 2015). Additionally, osteo-odontogenic genes, $D m p-1, D s p p$, and $B s p$, were examined. Those markers have been previously reported as important factors for bone and dentin formation (Hwang et al., 2008; Ching et al., 2017). Following differentiation, the CopGFP cells expressed statistically higher levels of Dmp-1, Dspp, and Bsp, compared to the VEGFR-2 shRNA cells. This demonstrate that the VEGFR-2 shRNA DPSCs were unable to differentiate into the osteo-odontogenic lineage in vitro. Taken together, this suggests that VEGFR-2 may play an important role in osteo-odontogenic potential of DPSCs.

To further investigate whether VEGF-A signaling via VEGFR2 directly induces odontoblastic differentiation of DPSCs, the CopGFP and VEGFR-2 shRNA DPSCs were cultured in VEGF media and evaluated by ALP and Alizarin Red S staining. A few CopGFP cells only demonstrated positive ALP staining; however, none of VEGFR-2 shRNA cells showed a positive result. Moreover, neither CopGFP cells nor VEGFR-2 shRNA cells exhibited the positive Alizarin Red $\mathrm{S}$ staining. This indicates that VEGF-A only cannot induce a complete and mature osteoodontogenic differentiation. Instead, VEGF-A might facilitate or "prime" DPSCs for the early stages of differentiation but it seems insufficient on its own to induce full osteo-odontogenic differentiation. These results are consistent with previous studies showing that exogenous VEGF enhances proliferation and early differentiation of DPSCs (D'Alimonte et al., 2011; Forgues et al., 2019). Nevertheless, our current study helps us differentiate the role of VEGFR-2 in the osteo-odontogenic ability of DPSCs, independent of VEGF-A.

To confirm our in vitro differentiation, the CopGFP and VEGFR-2 shRNA DPSCs mixed with hydroxyapatite/tricalciumphosphate (HAp/TCP) were subcutaneously transplanted in the dorsum of Rag-1 knockout mice for 5 weeks. This knockout mouse model is immunodeficient due to an absence of B- and T-lymphocytes (Menoret et al., 2013), and thus a good model to avoid transplant rejection. The CopGFP DPSC transplants exhibited elongated and polarized OLCs with vascularized pulp-like structures, corresponding to several previous studies of DPSC transplants with osteoconductive HAp/TCP scaffolds (Gronthos et al., 2000, 2002). In contrast, the VEGFR-2 shRNA DPSC transplants showed only the formation of collagenous and fibrous tissues. Consequently, the CopGFP DPSC transplantation confirms a biological role of VEGFR-2 for DPSC odontogenic potential.

In addition to endothelial cells, VEGF signaling has been shown to exhibit an important function in osteoblasts (Deckers et al., 2000). Previous in vitro experiments suggested that VEGFR-2 plays a role in osteoblast differentiation and survival (Alonso et al., 2008). Recently, the role of VEGF signaling and intracellular VEGF in osteoblast differentiation have been reported (Liu et al., 2012). BMP-induced VEGF expression is an important mechanism during osteoblast differentiation and bone formation (Zelzer and Olsen, 2005). Unlike the osteoblast differentiation, the role of VEGFR-2 in odontoblastic differentiation of DPSCs is still undetermined. Our data showed that VEGFR-2 shRNA DPSCs cultured in BMP-2 media were unable to give rise into the osteo-odontogenic lineage. One possibility is that VEGFR2 signaling is necessary for up-regulation of BMP-2 receptors (BRII and BRII) and downstream signaling molecules (Smads), thus priming odontoblast precursors to be responsive to BMP-2 (Qin et al., 2012). Additionally, silencing VEGFR-2 in DPSCs led to reductions in VEGF-A levels. Therefore, impaired odontoblast differentiation of VEGFR-2 null cells may be due to synergist or independent effects of VEGF-A.

However, our studies showed that adding exogenous VEGF to treat CopGFP and VEGFR-2 shRNA cells did not induce complete odontogenic differentiation. This is corresponding to a previous study showing that treatment with recombinant VEGF does not affect osteoblastic and adipocytic differentiation in normal bone marrow derived MSCs and VEGF deficient MSCs (Liu et al., 2012). Altogether, this suggests the effects of VEGFR-2 are mediated by intracellular mechanisms, possibly including transcriptional regulation of BMP signaling proteins rather than by paracrine VEGF signaling. In addition to intracrine mechanisms, it is possible that DPSC-derived VEGF also affects the formation of dentin/pulp complex in vivo through enhanced angiogenesis (Wang et al., 2007). Nonetheless, the specific mechanism(s) of how VEGFR-2 affects odontoblast differentiation of DPSCs need to be further investigated.

In conclusion, our data originally identifies VEGFR-2 signaling as an important molecular pathway for odontoblastic differentiation in DPSCs. These results provide key evidence of the importance of VEGFR-2 in tooth development and highlight the potential of VEGFR-2 modulation to enhance dentin regeneration and tissue engineering as a promising clinical application such as targeted drug therapy and delivery for regenerative dentistry.

\section{DATA AVAILABILITY STATEMENT}

The raw data supporting the conclusions of this article will be made available by the authors, without undue reservation.

\section{ETHICS STATEMENT}

The animal study was reviewed and approved by University of Washington.

\section{AUTHOR CONTRIBUTIONS}

KJ and MR: writing and editing and study design. KJ, RC, and $\mathrm{AH}$ : experimentation. KJ, RC, and MR: data analysis. All authors contributed to the article and approved the submitted version. 


\section{FUNDING}

Bridge funding awarded to MR from the Department of Pathology at Albert Einstein College of Medicine was used to finish some of the studies in this manuscript.

\section{ACKNOWLEDGMENTS}

We would like to thank Nicholas Ieronimakis, Ambika Gunaje, Grace Fortes Monis, Jonathan H. Tsui, and

\section{REFERENCES}

Alonso, V., De Gortazar, A. R., Ardura, J. A., Andrade-Zapata, I., Alvarez-Arroyo, M. V., and Esbrit, P. (2008). Parathyroid hormone-related protein (107-139) increases human osteoblastic cell survival by activation of vascular endothelial growth factor receptor-2. J. Cell. Physiol. 217, 717-727. doi: 10.1002/jcp.21547

Andrukhov, O., Behm, C., Blufstein, A., and Rausch-Fan, X. (2019). Immunomodulatory properties of dental tissue-derived mesenchymal stem cells: implication in disease and tissue regeneration. World J. Stem Cells 11, 604-617. doi: 10.4252/wjsc.v11.i9.604

Berendsen, A. D., and Olsen, B. R. (2014). How vascular endothelial growth factorA (VEGF) regulates differentiation of mesenchymal stem cells. J. Histochem. Cytochem. 62, 103-108. doi: 10.1369/0022155413516347

Breyer, A., Estharabadi, N., Oki, M., Ulloa, F., Nelson-Holte, M., Lien, L., et al. (2006). Multipotent adult progenitor cell isolation and culture procedures. Exp. Hematol. 34, 1596-1601. doi: 10.1016/j.exphem.2006.07.013

Bronckaers, A., Hilkens, P., Fanton, Y., Struys, T., Gervois, P., Politis, C., et al. (2013). Angiogenic properties of human dental pulp stem cells. PLoS One 8:e0071104. doi: 10.1371/journal.pone.0071104

Buettmann, E. G., McKenzie, J. A., Migotsky, N., Sykes, D. A. W., Hu, P., Yoneda, S., et al. (2019). VEGFA from early osteoblast lineage cells (Osterix plus) is required in mice for fracture healing. J. Bone Miner. Res. 34, 1690-1706. doi: 10.1002/jbmr.3755

Ching, H. S., Luddin, N., Ab Rahman, I., and Ponnuraj, K. T. (2017). Expression of odontogenic and osteogenic markers in DPSCs and SHED: a review. Curr. Stem Cell Res. Ther. 12, 71-79. doi: 10.2174/1574888x11666160815095733

Clark, D., Wang, X., Chang, S., Czajka-Jakubowska, A., Clarkson, B. H., and Liu, J. (2015). VEGF promotes osteogenic differentiation of ASCs on ordered fluorapatite surfaces. J. Biomed. Mater. Res. Part A 103, 639-645. doi: 10.1002/ jbm.a.35215

Dahlin, R. L., Ni, M., Meretoja, V. V., Kasper, F. K., and Mikos, A. G. (2014). TGF-beta3-induced chondrogenesis in co-cultures of chondrocytes and mesenchymal stem cells on biodegradable scaffolds. Biomaterials 35, 123-132. doi: 10.1016/j.biomaterials.2013.09.086

D’Alimonte, I., Nargi, E., Mastrangelo, F., Falco, G., Lanuti, P., Marchisio, M., et al. (2011). Vascular endothelial growth factor enhances in vitro proliferation and osteogenic differentiation of human dental pulp stem cells. J. Biol. Regul. Homeost. Agents 25, 57-69.

Deckers, M. M. L., Karperien, M., van der Bent, C., Yamashita, T., Papapoulos, S. E., and Lowik, C. W. G. M. (2000). Expression of vascular endothelial growth factors and their receptors during osteoblast differentiation. Endocrinology 141, 1667-1674. doi: 10.1210/en.141.5.1667

Duan, X. C., Bradbury, S. R., Olsen, B. R., and Berendsen, A. D. (2016). VEGF stimulates intramembranous bone formation during craniofacial skeletal development. Matrix Biol. 52-54, 127-140. doi: 10.1016/j.matbio.2016.02.005

Eichmann, A., and Simons, M. (2012). VEGF signaling inside vascular endothelial cells and beyond. Curr. Opin. Cell Biol. 24, 188-193. doi: 10.1016/j.ceb.2012. 02.002

Fernandes, T. L., Shimomura, K., Asperti, A., Pinheiro, C. C. G., Caetano, H. V. A., Oliveira, C. R. G. C. M., et al. (2018). Development of a novel large animal model to evaluate human dental pulp stem cells for articular cartilage treatment. Stem Cell Rev. Rep. 14, 734-743. doi: 10.1007/s12015-018-9820-2
Sara Parent for helping us in the research project. Puangwan Laptanasupkun for useful comments in tooth sections.

\section{SUPPLEMENTARY MATERIAL}

The Supplementary Material for this article can be found online at: https://www.frontiersin.org/articles/10.3389/fcell.2021. 665886/full\#supplementary-material

Forgues, C., Mullins, E., and Kingsley, K. (2019). Effects of vascular endothelial growth factor (VEGF) on dental pulp stem cells (DPSC). Curr. Res. Med. 9, 1-8. doi: 10.3844/amjsp.2019.1.8

Gregoire, F. M. (2001). Adipocyte differentiation: from fibroblast to endocrine cell. Exp. Biol. Med. 226, 997-1002. doi: 10.1177/153537020122601106

Gronthos, S., Brahim, J., Li, W., Fisher, L. W., Cherman, N., Boyde, A., et al. (2002). Stem cell properties of human dental pulp stem cells. J. Dent. Res. 81, 531-535. doi: 10.1177/154405910208100806

Gronthos, S., Graves, S. E., Ohta, S., and Simmons, P. J. (1994). The STRO-1+ fraction of adult human bone marrow contains the osteogenic precursors. Blood 84, 4164-4173.

Gronthos, S., Mankani, M., Brahim, J., Robey, P. G., and Shi, S. (2000). Postnatal human dental pulp stem cells (DPSCs) in vitro and in vivo. Proc. Natl. Acad. Sci. U.S.A. 97, 13625-13630. doi: 10.1073/pnas.240309797

Guryanova, O. A., Makhanov, M., Chenchik, A. A., Chumakov, P. M., and Frolova, E. I. (2006). Optimization of a genome-wide disordered lentivector-based short hairpin RNA library. Mol. Biol. 40, 396-405. doi: 10.1134/S002689330603006x

$\mathrm{Hu}, \mathrm{K}$., and Olsen, B. R. (2016a). Osteoblast-derived VEGF regulates osteoblast differentiation and bone formation during bone repair. J. Clin. Investig. 126, 509-526. doi: 10.1172/Jci82585

$\mathrm{Hu}, \mathrm{K}$., and Olsen, B. R. (2016b). The roles of vascular endothelial growth factor in bone repair and regeneration. Bone 91, 30-38. doi: 10.1016/j.bone.2016.06.013

Hu, Z. M., Peel, S. A. F., Sandor, G. K. B., and Clokie, C. M. L. (2004) The osteoinductive activity of bone morphogenetic protein (BMP) purified by repeated extracts of bovine bone. Growth Fact. 22, 29-33. doi: 10.1080/ 08977190410001682854

Huang, A. H. C., Chen, Y. K., Lin, L. M., Shieh, T. Y., and Chan, A. W. S. (2008). Isolation and characterization of dental pulp stem cells from a supernumerary tooth. J. Oral Pathol. Med. 37, 571-574. doi: 10.1111/j.1600-0714.2008.00654.x

Hwang, Y. C., Hwang, I. N., Oh, W. M., Park, J. C., Lee, D. S., and Son, H. H. (2008). Influence of TGF-betal on the expression of BSP, DSP, TGF-betal receptor I and Smad proteins during reparative dentinogenesis. J. Mol. Histol. 39, 153-160. doi: 10.1007/s10735-007-9148-8

Jacobsen, K. A., Al-Aql, Z. S., Wan, C., Fitch, J. L., Stapleton, S. N., Mason, Z. D., et al. (2008). Bone formation during distraction osteogenesis is dependent on both VEGFR1 and VEGFR2 signaling. J. Bone Miner. Res. 23, 596-609. doi: 10.1359/Jbmr.080103

Janebodin, K., Horst, O. V., Ieronimakis, N., Balasundaram, G., Reesukumal, K., Pratumvinit, B., et al. (2011). Isolation and characterization of neural crestderived stem cells from dental pulp of neonatal mice. PLoS One 6:e27526. doi: 10.1371/journal.pone.0027526

Janebodin, K., Zeng, Y., Buranaphatthana, W., Ieronimakis, N., and Reyes, M. (2013). VEGFR2-dependent angiogenic capacity of pericyte-like dental pulp stem cells. J. Dent. Res. 92, 524-531. doi: 10.1177/002203451348 5599

Jorgensen, N. R., Henriksen, Z., Sorensen, O. H., and Civitelli, R. (2004) Dexamethasone, BMP-2, and 1,25-dihydroxyvitamin D enhance a more differentiated osteoblast phenotype: validation of an in vitro model for human bone marrow-derived primary osteoblasts. Steroids 69, 219-226. doi: 10.1016/j. steroids.2003.12.005

Kabatas, S., Demir, C. S., Civelek, E., Yilmaz, I., Kircelli, A., Yilmaz, C., et al. (2018). Neuronal regeneration in injured rat spinal cord after human dental pulp 
derived neural crest stem cell transplantation. Bratisl. Lek. Listy 119, 143-151. doi: 10.4149/BLL_2018_028

Kerkis, I., Ambrosio, C. E., Kerkis, A., Martins, D. S., Zucconi, E., Fonseca, S. A. S., et al. (2008). Early transplantation of human immature dental pulp stem cells from baby teeth to golden retriever muscular dystrophy (GRMD) dogs: local or systemic? J. Transl. Med. 6:35. doi: 10.1186/1479-5876-6-35

Liu, Y. Q., Berendsen, A. D., Jia, S. D., Lotinun, S., Baron, R., Ferrara, N., et al. (2012). Intracellular VEGF regulates the balance between osteoblast and adipocyte differentiation. J. Clin. Investig. 122, 3101-3113. doi: 10.1172/ Jci61209

Luo, L. H., He, Y., Wang, X. Y., Key, B., Lee, B. H., Li, H. Q., et al. (2018). Potential roles of dental pulp stem cells in neural regeneration and repair. Stem Cells Int. 2018:1731289. doi: 10.1155/2018/1731289

Martinez-Sarra, E., Montori, S., Gil-Recio, C., Nunez-Toldra, R., Costamagna, D., Rotini, A., et al. (2017). Human dental pulp pluripotent-like stem cells promote wound healing and muscle regeneration. Stem Cell Res. Ther. 8:175. doi: 10.1186/s13287-017-0621-3

Marupanthorn, K., Tantrawatpan, C., Kheolamai, P., Tantikanlayaporn, D., and Manochantr, S. (2017). Bone morphogenetic protein-2 enhances the osteogenic differentiation capacity of mesenchymal stromal cells derived from human bone marrow and umbilical cord. Int. J. Mol. Med. 39, 654-662. doi: 10.3892/ijmm. 2017.2872

Menoret, S., Fontaniere, S., Jantz, D., Tesson, L., Thinard, R., Remy, S., et al. (2013). Generation of Rag1-knockout immunodeficient rats and mice using engineered meganucleases. FASEB J. 27, 703-711. doi: 10.1096/fj.12-21 9907

Moore, C. B., Guthrie, E. H., Huang, M. T., and Taxman, D. J. (2010). Short hairpin RNA (shRNA): design, delivery, and assessment of gene knockdown. Methods Mol. Biol. 629, 141-158. doi: 10.1007/978-1-60761-657-3_10

Neufeld, G., Cohen, T., Gengrinovitch, S., and Poltorak, Z. (1999). Vascular endothelial growth factor (VEGF) and its receptors. FASEB J. 13, 9-22.

Paz, A. G., Maghaireh, H., and Mangano, F. G. (2018). Stem cells in dentistry: types of intra- and extraoral tissue-derived stem cells and clinical applications. Stem Cells Int. 2018:4313610. doi: 10.1155/2018/4313610

Qin, W., Yang, F., Deng, R., Li, D. D., Song, Z., Tian, Y. G., et al. (2012). Smad 1/5 is involved in bone morphogenetic protein-2-induced odontoblastic differentiation in human dental pulp cells. J. Endodontics 38, 66-71. doi: 10. 1016/j.joen.2011.09.025

Sabokbar, A., Millett, P. J., Myer, B., and Rushton, N. (1994). A rapid, quantitative assay for measuring alkaline phosphatase activity in osteoblastic cells in vitro. Bone Miner. 27, 57-67. doi: 10.1016/s0169-6009(08)80187-0

Shi, X., Mao, J., and Liu, Y. (2020). Concise review: pulp stem cells derived from human permanent and deciduous teeth: biological characteristics and therapeutic applications. Stem Cells Transl. Med. 9, 445-464. doi: 10.1002/sctm. 19-0398

Song, I. H., Caplan, A. I., and Dennis, J. E. (2009). In vitro dexamethasone pretreatment enhances bone formation of human mesenchymal stem cells in vivo. J. Orthop. Res. 27, 916-921. doi: 10.1002/jor.20838

Sui, B., Wu, D., Xiang, L., Fu, Y., Kou, X., and Shi, S. (2020). Dental pulp stem cells: from discovery to clinical application. J. Endod. 46, S46-S55. doi: 10.1016/ j.joen.2020.06.027

Tomasello, L., Mauceri, R., Coppola, A., Pitrone, M., Pizzo, G., Campisi, G., et al. (2017). Mesenchymal stem cells derived from inflamed dental pulpal and gingival tissue: a potential application for bone formation. Stem Cell Res. Therapy 8:179. doi: 10.1186/s13287-0170633-z

Ullah, I., Choe, Y. H., Khan, M., Bharti, D., Shivakumar, S. B., Lee, H. J., et al. (2018). Dental pulp-derived stem cells can counterbalance peripheral nerve injuryinduced oxidative stress and supraspinal neuro-inflammation in rat brain. Sci. Rep. 8:15795. doi: 10.1038/s41598-018-34151-x

Victor, A. K., and Reiter, L. T. (2017). Dental pulp stem cells for the study of neurogenetic disorders. Hum. Mol. Genet. 26, R166-R171. doi: 10.1093/hmg/ ddx208

Wang, Y., Wan, C., Deng, L., Liu, X., Cao, X., Gilbert, S. R., et al. (2007). The hypoxia-inducible factor alpha pathway couples angiogenesis to osteogenesis during skeletal development. J. Clin. Invest. 117, 1616-1626. doi: 10.1172/ JCI31581

Yamada, Y., Nakamura-Yamada, S., Kusano, K., and Baba, S. (2019). Clinical potential and current progress of dental pulp stem cells for various systemic diseases in regenerative medicine: a concise review. Int. J. Mol. Sci. 20:1132. doi: $10.3390 /$ ijms 20051132

Zelzer, E., and Olsen, B. R. (2005). Multiple roles of vascular endothelial growth factor (VEGF) in skeletal development, growth, and repair. Curr. Top. Dev. Biol. $65,169-178$.

Conflict of Interest: The authors declare that the research was conducted in the absence of any commercial or financial relationships that could be construed as a potential conflict of interest.

Copyright $\odot 2021$ Janebodin, Chavanachat, Hays and Reyes Gil. This is an openaccess article distributed under the terms of the Creative Commons Attribution License (CC BY). The use, distribution or reproduction in other forums is permitted, provided the original author(s) and the copyright owner(s) are credited and that the original publication in this journal is cited, in accordance with accepted academic practice. No use, distribution or reproduction is permitted which does not comply with these terms. 